\title{
HIGH FEED TURNING: ROUGHING AND FINISHING WITH THE SAME INSERT?
}

\author{
Viktor RÁCZI, ${ }^{1}$ Csenge HUSZÁK, ${ }^{2}$ Sándor SIPOS ${ }^{3}$ \\ Óbuda University, Donát Bánki Faculty of Mechanical Engineering, Inst. of Materials and Manufacturing \\ Sciences, Budapest, Hungary \\ ${ }^{1}$ raczi.viktor@bgk.uni-obuda.hu \\ ${ }^{2}$ huszak.csenge@bgk.uni-obuda.hu \\ ${ }^{3}$ sipos.sandor@bgk.uni-obuda.hu
}

\begin{abstract}
The tools of multi-directional machining, having appeared in the recent years, have revolutionised turning operations. The chip removal of high feed roughing and finishing inserts is so specialised, that new formulas have to be introduced instead of those used so far. In this paper, the result of tests carried out up till now will be summarised; furthermore, a proposal will be made on the description, analysis and calculation of force demand of multi-directional inserts as well as the roughness of the surface being prepared during machining.
\end{abstract}

Keywords: multi-directional turning, chip development, force effects, microgeometry.

\section{Introduction}

Faster, cheaper, more precision - every industrial company faces these challenges, yet they are hardly compatible with each other in day-to-day industrial activity. In addition there are increasingly strict requirements in connection with process safety and environmental protection. Multi-directional high feed turning has been established by the demand to produce difficult component-configurations, using fewer tools. Some publications have already been prepared by the authors about turning tools working based on the new principle (PrimeTurning) $[1,2]$. The present study will summarise the test results and proposals will be made on the description, analysis and calculation of force demand in multi-directional tools as well as the unevenness of the surface being prepared during the turning process.

\section{Surface formation with PrimeTurn- ing $^{\mathrm{TM}}$ tools}

The CoroTurn Prime "B" type tools are primarily intended to machine surfaces in longitudinal and transverse direction or shaped (mainly taper) forms, having a low inclination angle. A special feature of the tool edge geometry is that the direction of the feed has a reverse direction in the case of rough- ing and finishing. This modifies not only the position and function of edges, but the high feed turning changes the nature of surface formation, the chip detachment (chip development, force effects, etc.), furthermore the kinematic imprint of the tool will be modified during the formation of the turned surface. The formulas published in literature don't describe the phenomena mentioned earlier; therefore the widespread use of this procedure is impeded.

In order to study the novel tool, a set of experiments has been carried out, applying a tool holder (CP-25BR-2525-11) and compatible insert (CP-B1108-M5 4325). In the turning tests free-machining, steel sample pieces were used with the following features: the dimension was $\phi 60 \times 160 \mathrm{~mm}$, the material is $11 \mathrm{SMn} 30+\mathrm{C}$ with harness of HB150. The tests were performed on a BNC1840 CNC-lathe (Dugard Eagle) without applying cooling lubricant.

Concerning the possibilities of the machine and tool, the tests were carried out at a constant cutting speed level $\left(v_{c}=250 \mathrm{~m} / \mathrm{min}\right.$ ). Using DoE (Design of Experiments), the turning tests were conducted in ten different combinations: the values of depth of cut were varied at three $(a=0.5 ; 1.0 ; 1.5 \mathrm{~mm})$, the feed rate values at four levels so that, in case of roughing, it had a value of $f=0.3 \ldots 1.2 \mathrm{~mm}$, while in case of finishing between $0.2 \ldots 0.6 \mathrm{~mm}$. Compared to the commonly configured tools, the last men- 
tioned are nearly double values, meaning a high degree of increase in productivity. This creates an advantage especially in the automobile industry as in high-volume production, every moment saved in the production is important.

\subsection{Specific features of the chip development}

The geometric features of the CP-B1108 insert became known by scanning (profile projector: Mitutoyo PJ-H30000F) at very small distances (for example, $1 \mu \mathrm{m}$ ), and modelling (software: Mitutoyo N-COCMOS 2.4 and Catia P3V5R21) the contour points, building the edges. We emphasize that there were differences between the values measured by us and those published in the tutorial matter [3].

In case of roughing, the main edge of the insert has two sections, having two different point angles $\left(25^{\circ}\right.$ and $5^{\circ}$ ) and connected by a large-scale radius. The corner radius in the traditional sense continues in minor cutting edge, having also two different point angles. According to our measurements, the insert included angle (EPSR), effectively performing the cutting process, is approx. $84^{\circ}$, the whole EPSR is $40^{\circ}$, while corner radius is approx. $0,6 \mathrm{~mm}$. These features have a determining effect on the material detachment as the thickness of the developing chip is very small and so the width is suitably large. In Figure 1. the geometric data, determined by insert measurement, the CAD-model of theoretical chip cross section and the shape of a detached swarf are shown.

During finishing the tool edges - as a result of the opposite feed direction - are changed and work as a VNMG insert geometry, "implanted" in the traditional CNMG one. Its features are: the lead angle (KAPR) is approx. $93^{\circ}$, the minor cutting edge angle (MCEA) is approx. $2,5^{\circ}$, while the value of corner radius remains (naturally) the same. As a result, the cross section of the swarf to be detached, does not differ from the value, being normal in case of ISOshaped insert (Figure 2.).

The chip charts, made from detached chip, are demonstrated in Figure 3. The cross section of the detached chips, analysed under roughing conditions, varied between $0.45 . .1 .8 \mathrm{~mm}^{2}$, in seven cases out of ten there was a favourable broken chip. In the case of setting the highest feed values $(f \geq 1 \mathrm{~mm})$ dangerously coiled, tangled, flowing chip formed which could only be "stopped" by the enclosure of CNC-machine. The chip-breaking performance is caused by the individual design of the rake face of the insert: the shape of M5 chip-breaker will be pressed into the swarf, forcing the material to additionally deform, reducing the width of the chip that is about to be detached [1]. Unfavourable chip shape developed only at highest feed value setting.

\subsection{Cutting force effects}

The force components, developed during the turning operation, were measured with dynamometer, type: KISTLER 9021A and were evaluated with Dynoware software. The force components $F_{c}, F_{f}$ and $F_{p}$ were compared only at one cutting speed and depth of cut value, therefore the power function model can be calculated with the following formula:

$$
F_{j k}=C_{F j k} \cdot f^{x_{F j k}}[N]
$$

where $j$ refers to the force component, while $k$ points to roughing or finishing.

The coefficient of determination of models indicates that there is a very small difference between the measured and calculated values. The results, gained after calculation, are shown in Figure 4. As shown in Figure 4a. the cutting force, developed during roughing, is $10 \%$ greater on average, compared to the forces occurring during the finishing. This can be explained by the shape of the chip: the width of the chip, detached during roughing process, is in relation with the prolonged contact between tool edge and workpiece; the low chip thickness results in significant increase of specific cutting force.

It became clear from our tests that the turning operation with increased feed values $(f \geq 0,9 \mathrm{~mm})$ requires a significant Pc cutting performance. The measured (and modelled by one-factor power function) values of feed force $\left(F_{f}\right)$ components can be explained by other reasons. When finishing, the tool works with a greater lead angle (see Figure $2 \mathbf{b}$.), and it results - in full accordance with cutting theory-in increased force effects. On the other hand, in case of roughing the lead angle has a smaller value and requires lower $F_{f}$ force component.

The roughing and finishing operation, carried out with the same tool, has to be compared from the point of view of turned surface accuracy, too. The force effects, developing during the cutting process, may cause form error and/or sizing defect. The greatest component is the cutting force $\left(F_{c}\right)$ and it causes a second degree error, while the $F_{p}$ passive force components, effecting in the direction of depth of cut, (may) lead to first degree error. When turning "slim" shafts, having a relative small diameter, the characteristic longitudinal form error is the "barrel shape form".

In Figure $4 \mathrm{~b}$. the passive force is shown during roughing and finishing (the developing Fc cutting 
force is demonstrated for comparison only). As a result of the unusual low lead angle data, the value of $F_{p}$ is two-thirds of $F_{c}$ in case of roughing; therefore, in case of "slim" pieces it may cause even a significant form error of some hundredths of a mm [1] In case of the finishing operation, the edges are changed, the point angles are modified. As a result, there is a decrease in the passive force (it is only $30 \%$ of the main cutting force), therefore the form error, forming during the turning process, is not notable.

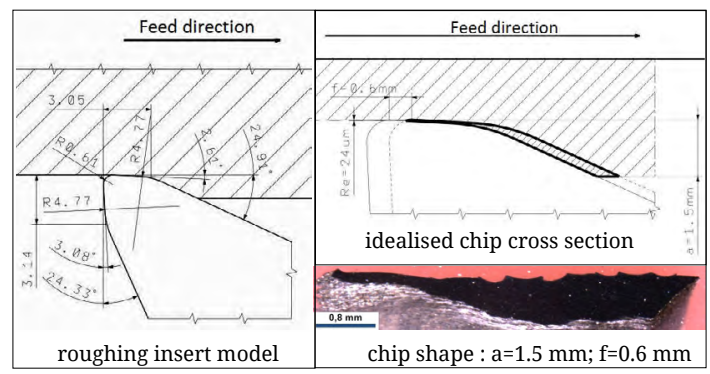

Figure 1. The roughing features of CoroTurn Prime " $B$ " insert

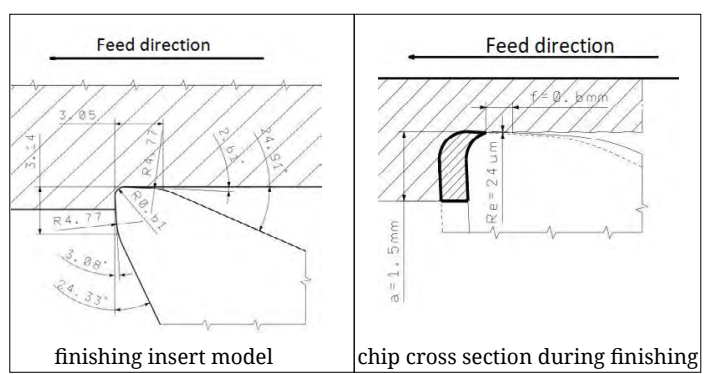

Figure 2. The finishing features of CoroTurn Prime " $B$ " insert

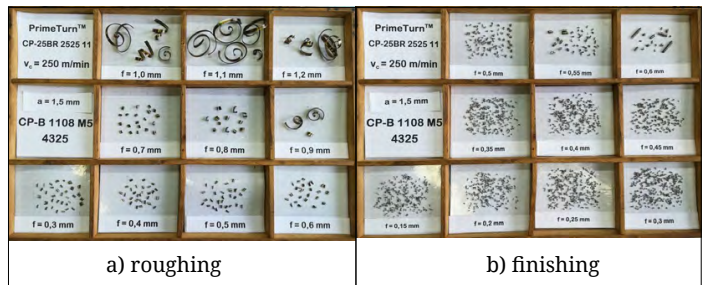

Figure 3. The chip charts in case of different machining methods $\left(v_{c}=250 \mathrm{~m} / \mathrm{min} ; a=1.5 \mathrm{~mm}\right)$

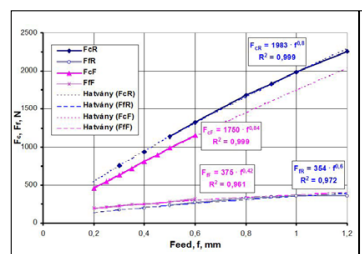

a) active force components

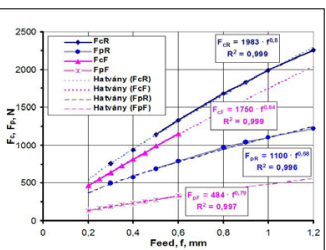

b) passive force effect
Figure 4. The force components, measured in case of roughing and finishing $\left(v_{c}=250 \mathrm{~m} / \mathrm{min} ; a=1.5 \mathrm{~mm}\right)$

\section{Microgeometric characteristics}

In this study we are not discussing elements of layer properties, only the microgeometric features of surface quality. The development of the $\mathrm{Wt}$ waviness values (of the filtered profile) of turned surface, machined with " $\mathrm{B}$ " tool, is included in the literature [1]; therefore we focus on the analysis of unevenness of profiles developed during roughing and finishing operations.

The measurements were carried out on Perthometer PRK Concept 2D/3D surface tester equipment, the characteristic roughness parameters were determined by MarSurf XCR-20 software. Three-three roughness profiles were recorded for every data setting; so the following diagrams contain average values [2].

In Hungarian practice it's usual to characterise the machined surface by indicating the arithmetical roughness parameters, mainly with average roughness $(\mathrm{Ra})$ and unevenness-height (Rz). Although the Ra parameter is more common (on the different measuring sections it may have a nearly constant value), it doesn't show the characteristic and apparently important differences between the surface sections [4]. We focused on the analysis of the unevenness-height, expressing the characteristics of roughness profile in a better way. This parameter is increasingly used by suppliers in the automobile and aerospace industry, and in tool and die making production.

In Figure 5. the $R z$ values, measured in case of roughing and finishing operations are shown, and the roughness model, proposed by us earlier [1], and even more, the calculated values of Rtheor.

$$
R z=A \cdot f^{2}+B \cdot f+C[\mu m]
$$

Based on the figure it can be noted that the theoretical roughness, calculated with the following, so called Bauer-formula, cannot be connected with the $\mathrm{Rz}$ values determined with measurements.

$$
\mathrm{R}_{\text {theor }} \approx 125 \cdot \mathrm{f}^{2} / \operatorname{REPS}[\mu \mathrm{m}]
$$

The linear element $B \cdot f$ of the (2) equation expresses a fact of cutting theory that in these cases the minor cutting edge (and the corner radius, REPS) has a determining role in the formation of surface profile machined with turning operations.

In case of roughing, a strong correlation can be stated among the roughness values, calculated with the mentioned formula, and measured $R z$ values. In case of finishing, this function shows a moderate relationship, but the unevenness-height can be characterised - almost completely independently from the high values of feed - with favourably low (approx. $R z=4 \mu \mathrm{m}$ ) values. 
As can be seen well from development of the chart lines, when turning with the " $\mathrm{B}$ " tool a surprisingly wide range of optimum feed rates can be observed in the case of roughing and finishing, too. When setting these values, minimum unevenness can be achieved, thanks to the specific design of tool edges.

The most favourable value of feed can be calculated from the constants of the model $\left(f_{\text {opt }}=-0.5 \mathrm{~B} / \mathrm{A}\right)$, and it is $f=0.67 \mathrm{~mm}$ in case of roughing, and $f=0.43 \mathrm{~mm}$ in finishing.

In most cases, on the component drawings only one ( $R a$ or $R z$ ) parameter is given to characterise the roughness of the machined (turned) surface. In order to convert between $R a$ and $R z$, the formula $R z=4 \times R a$ served as a professional foundation in the last six decades. However, this ratio has only a limited validity and it's acceptable only under roughing conditions. It cannot be applied in case of finishing and fine-turning operations [4].

In Figure 6., the values of the $R z / R a$ ratio are shown, measured during the tests. As it can be observed, the $R z / R a$ is considerably greater than four in case of turning, carried out in both directions and at every feed rate. It is especially surprising that this ratio exceeds the "mystical" multiplier " 4 " even in case of roughing machining method ( $f>>0.3 \mathrm{~mm}$ ). This results from the special tool edge design, too.

In this article - due to space limitations -we cannot introduce our results by means of which we could create a set of parameters for appropriately characterising the special profiles of turned surfaces. It builds on one hand on the lesser-used roughness parameters ( $R p, R v, R p / R z, R p / R v)$, on the other hand on the static parameters of the profile. In case of surfaces turned with roughing and finishing operations, the topological map of profile, characterised by the parameters of Rsk-Rku, and the profile bearing length ratio (RMr) have to be analysed. With these measured data firstly we can describe the present condition of the surface in more detail than ever, secondly we can draw conclusions regarding the future behaviour (e.g. durability, wear etc.) of the surface of the component [4].

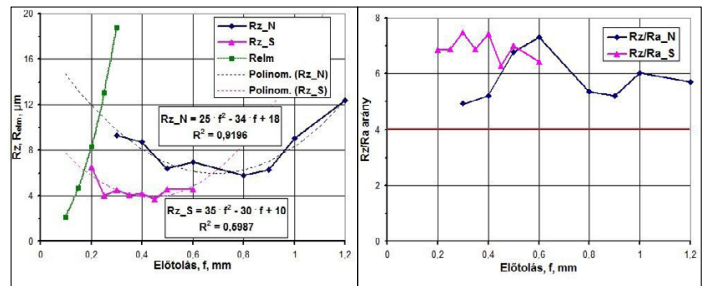

Figure 5. The development Figure 6. The developof roughness features $\left(v_{c}\right.$ $=250 \mathrm{~m} / \mathrm{min} ; a=1.5 \mathrm{~mm}$ )

\section{Conclusions}

The use of tools developed with significant innovation and/or working based on new principles, may only spread if their launch is supported by several tests and results of the industrial practice. It is especially true for the revolutionary new " $\mathrm{B}$ " tool as the knowledge and experience concerning its usability, is limited for the users. In this article we have analysed the specific features characterising the surface formation of multi-directional longitudinal turning, working in two feed directions (to the left or right) and two ways of operation (roughing and finishing).

With measurements we demonstrated that due to the specific tool geometry, the role of edges are changed during roughing or finishing, that results in an individual chip detachment. The position of the edges and the values of point angles have a decisive influence on the developing force effects and the roughness marks left on the machined surface. To describe the $F_{c}, F_{p}$ and $F_{p}$ force components, the well-known power function model was used. Due to the unusually low value of point angle, the passive force component increases when roughing, and it leads to a longitudinal ("barrel" shape) form error.

To be able to plan roughing and finishing technology in a safer way, as a proxy the (2) $R z$ equation has been established by the authors. However, we would like to emphasise that it is not possible to describe the machined surfaces with a single, "universal" measure, able to characterise the condition of the examined profile from every point of view. The relation of parameters (Rp/Rz), the topological map, characterised by the double parameter of Rsk and $\mathrm{Rku}$, and the bearing capacity of profile have to be analysed.

We are going to report about these as well as the results of tests, concerning a wider range of workpiece material qualities (tempered or corrosion-resistant steels, HRSA-materials etc.), later.

\section{References}

[1] Ráczi V., Farkas, G., Sipos, S.: Chip removal specialities in multi-directional turning. Müszaki Tudományos Közlemények 9. (2018) 207-210.

[2] Farkas G., Sipos S., Ráczi V.: A felületképzés elemzése többirányú esztergáláskor. Int. Eng. Symp. at Banki, Óbuda University, 21.11.2018. Section I.

[3] New definitions of Turning SANDVIK Coromant (offitional ppt), 2017. 28 slides

[4] Palásti-Kovács B., Sipos S., Biró Sz.: The Mysteries of the Surface. First Part: The Characteristic Features of the Microgeometry of the Machined Surface, Acta Polytechnica Hungarica, 11/5. 5-24. https://doi.org/10.1270000/APH11.05.2014.05.1 